\section{Haematological abnormalities and risk of COVID-19 infection in adult patients attending primary healthcare settings}

Ehab Hamed, Mohamed Ahmed Syed, Ahmed Sameer Alnuaimi, Mohammed Soliman, Bayan Alemrayat, Amina Ali Mohamed Muktar, AlAnoud Saleh AlFehaidi, Hamda Abdulla AlQotba

Qatar University Health Centre, Primary Health Care Corporation, Doha, Qatar

\section{Abstract \\ Centres for Disease Control and} prevention $(\mathrm{CDC})$ reports that there are limited data and information about the impact of underlying medical conditions and the risk of infection. To date, there are no studies that report on the risk of infection among patients with haematological diseases or abnormalities. This cross-sectional study reports on the baseline complete blood count in patients attending publicly funded primary care settings with a diagnosis of suspected COVID-19 infections in the state of Qatar. The study will report on the descriptive characteristics of the population, including gender, age and prior abnormalities to their blood test results. We will compare the results of those with positive and negative PCR test results, where appropriate. Nine hundred sixty-two adult patients attended publicly funded primary health care settings in the state of Qatar between February the 10th and April the 30th 2020 with a diagnosis of suspected COVID-19 infections had prior recorded blood investigations in the last six months and were included in this study. The population was young, mean of age is $38.8 \pm 11.6$. (Median: 36 [Min: 19 Max: 85]). Complete blood count of the sample had minimal missing data points. Females were more presented in our samples, Female ( $\mathrm{n}=560,58.21 \%)$ and Male $(n=402,41.79 \%)$. Most of our sample had a documented PCR test result, negative $(\mathrm{n}=831,86.38 \%)$; positive $(\mathrm{n}=123,12.79 \%)$ and missing $(\mathrm{n}=8,0.83 \%)$. Low haemoglobin values $(n=265,27.5 \%)$ and low red blood cell count $(n=170,17.7 \%)$ were the most prevalent complete blood count abnormality in the population. Leukopenia was less common $(n=50,8.2 \%)$. Most of the population had normal platelet count $(n=895,93 \%)$. Gender was the most influential factor in our sample to increase the odds of having a positive PCR test results; males were more likely to be affected ( $\mathrm{P}<0.001$, Chi-square test) (OR 2.56, 95\% CI 1.73-3.77). Categories for haematological abnormalities were not associated with increased risk of having a positive PCT test result. In a population attending primary healthcare settings with early presentation of symptoms of COVID-19 infection, the risk of infection among our cohort was not affected by the prior haematological values of those patients. Gender was the most influential parameter in the risk of infection in our population. Analysis of the results using gender-specific categories for different haematological parameters suggested that patients with abnormal haematological values were not at increased risk of having a positive COVID-19 infection.

\section{Introduction}

To date, there are no studies that report on the risk of infection among patients with haematological diseases or abnormalities. Centres for Disease Control and prevention (CDC) reports thalassemia and an immunocompromised state as part of the conditions that might increase the risk of severe infection. The updated report note that there are limited data and information about the impact of underlying medical conditions and the risk of infection. ${ }^{1}$ It is assumed that infectious diseases often have haematological manifestation, which manifests as changes in laboratory haematological values. Patients with different haematological conditions are at increased risk of infection. Immunodeficiency state or immunesuppressant therapy is associated with increased risk of infections. ${ }^{2,3}$ Research suggest patients with sickle cell anaemia are nearly 19 times more likely to contract bacterial infections. ${ }^{4}$

Recent evidence suggests patients with hematopoietic system diseases are at a higher risk of severe COVID-19 infections. Many case reports describe severe infections in various haemoglobin disorders, including thalassemia ${ }^{5,6}$ and sickle cell anaemia. ${ }^{7-10}$ Patients with immune deficiencies or those who are immunosuppressed may be at increased risk of severe infection. ${ }^{1-13}$ Low platelet count is also associated with an increased risk of severe infection and mortality. ${ }^{14,15}$

COVID-19 infection affects the hematopoietic system with many haematological abnormalities reported. Leukopenia, leucocytosis, lymphopenia is the most common changes associated with COVID-19 infections. ${ }^{16,17}$ Those changes
Ehab Hamed, Consultant Family Medicine, Qatar University Health Centre, Primary Health Care Corporation, Doha, Qatar.

E-mail: eshamed@phcc.gov.qa

Key words: COVID-19, risk factors, haematology.

Acknowledgments: We acknowledge with gratitude the support we received from the research department and Primary Health Care Corporation.

Contributions: EH, MAS, ASA conceived and designed the analysis. ASA and EH contributed to designing and preforming the analysis. MAS and EH contributed to writing the paper. All authors contributed to the review and approval of the final manuscript.

Conflict of interest: The authors declare that there is no conflict of interest.

Ethics approval and conflict of interest: Anonymous data request approved by the department of clinical research, primary health care corporation with reference number PHCC/DCR/2020/04/031.

Consent to participate: Data request and analysis were anonymous, and no patient consent was required.

Availability of data and materials: Data subject to Primary Health Care Corporation policies.

Received for publication: 7 August 2020.

Accepted for publication: 30 October 2020.

This work is licensed under a Creative Commons Attribution-NonCommercial 4.0 International License (CC BY-NC 4.0).

(C) Copyright: the Author(s), 2020

Licensee PAGEPress, Italy

Hematology Reports 2020; 12:8829

doi:10.4081/hr.2020.8829

also serve as prognostic factors for disease progression. Patients with increased White Blood Cell (WBC) count, decreased lymphocyte and/or platelet counts suffered more severe disease and worse outcomes. ${ }^{18}$ In patients with haematological conditions, compensatory mechanisms are suboptimal to deal with such changes, which might explain the severe form of the disease in such conditions. Therefore, reporting on the risk of infections among patients with premorbid conditions would inform clinical decision making and risk stratification of patients with COVID-19 infections. ${ }^{19,20}$

This cross-sectional study reports on the baseline complete blood count in patients attending publicly funded primary care 
settings with a diagnosis of suspected COVID-19 infections in the state of Qatar.

The study will report on the descriptive characteristics of the population, including gender, age and prior abnormalities to their blood test results. We will compare the results of those with positive and negative PCR test results, where appropriate. The results might explain the variance in infection rates but more importantly assess the risk of infection among patients with abnormal haematological results.

Prior published work has examined the haematology and the biochemistry results, but the focus was more on the changes following the infection. The analysis would add to our understanding by analysing the pattern of infections in pre-established haematological abnormalities; the results may inform guidelines development. To the best of our knowledge, this is the first study to date to report on haematological parameters and risk of infection among COVID-19 patients.

\section{Materials and Methods}

We conducted a cross-sectional study using electronic medical records from publicly funded primary health care settings in the state of Qatar. Study participants included all adult patients with a recorded diagnosis of suspected COVID-19 infection attending primary health care settings between February the $10^{\text {th }}$ and $30^{\text {th }}$ of April 2020 with documented blood investigations results of more than one week and less than six months before the diagnosis in the electronic medical records system. Suspected case definition includes those patients with symptoms or close contact at the time of presentation. Prior complete blood test results are defined as complete blood tests more than one week before the attendance date and less than 6 months old. The reporting follows the observational routinely collected data guidelines.

\section{Variables}

Variables include age, gender, COVID19 PCR results and blood test results (including complete blood count and biochemistry results where available). We excluded missing data points on analysis by analysis basis. All available data points from patient's records were included, and no sampling was needed.

\section{COVID-19 variables}

Diagnostic and investigations codes were selected following consultation with the clinical information systems team and after review of the organisational guidelines. Outcomes included the total number of cases with a diagnosis of suspected COVID-19 case, number of cases with PCR test results. We excluded patients with no PCR test results. Comparison groups were established between patients with COVID-19 negative and positive PCR test to ensure the comparison between only confirmed cases.

\section{Blood test variables}

Complete blood count included White Blood Cells (WBCs), Red Blood Cells (RBCs), Platelets (Plts) as well as WBCs differential count and RBCs indices. All variables were treated as continuous variables, and WBCs, RBCs and Platelets were also coded in categorical variables where appropriate. Adult normal ranges were used to classify the categories of each. Normal ranges for WBCs count was of 4,000 to 11,000 . RBCs normal ranges for males were 4.7 to 6.1 million cells per microliter (cells/mcL) and for females 4.2 to 5.4 million cells $/ \mathrm{mcL}$. The normal range for haemoglobin was for men, 13.5 to 17.5 grams per decilitre and for women, 12.0 to 15.5 grams per decilitre. Finally, the normal platelet count ranges from 150,000 to 450,000 platelets per microliter of blood.

\section{Statistical methods}

All statistical analyses were performed using SPSS software version 25.0. The analyses included descriptive analysis of the demographics and testing rates among the population. Continuous variables are reported as the mean and standard deviation and categorical variables are described as frequency and percentage. The categorical variables were compared using the $\chi 2$ test. To compare the blood results means of both groups with positive and negative results, we used Independent Samples T-Test. Results are presented as mean with $95 \%$ Confidence Intervals (CIs) and $\mathrm{P}$ values of $<0.05$ is considered significant. Binominal logistic regression is used to adjust for gender as a confounder.

\section{Results}

\section{Overview}

Nine hundred sixty-two adult patients attended publicly funded primary health care settings in the state of Qatar between February the $10^{\text {th }}$ and April the $30^{\text {th }} 2020$ with a diagnosis of suspected COVID-19 infections had prior recorded blood investigations in the last six months and were included in this study. The population was young, mean of age is $38.8 \pm 11.6$ [Median: 36 - Min: 19 - Max: 85)]. Complete blood count of the sample had minimal missing data points.

Females were more presented in our samples, Female $(n=560,58.21 \%)$ and Male $(n=402,41.79 \%)$. Most of our sample had a documented PCR test result, negative $(\mathrm{n}=831,86.38 \%)$; positive $(\mathrm{n}=123,12.79 \%)$ and missing $(\mathrm{n}=8,0.83 \%)$ (Table 1). Low haemoglobin values $(n=265,27.5 \%)$ and low red blood cell count $(n=170,17.7 \%)$ were the most prevalent complete blood count abnormality in the population. Leukopenia was less common $(n=50,8.2 \%)$. Most of the population had normal platelet count (n $=895,93 \%)$ (Table 1).

Table 1. Descriptive of haematological characteristics among the study population.

\begin{tabular}{|c|c|}
\hline & $\begin{array}{c}\text { Overall } \\
(\mathrm{N}=962)(\%)\end{array}$ \\
\hline $\begin{array}{l}\text { Gender } \\
\text { Female } \\
\text { Male }\end{array}$ & $\begin{array}{l}560(58.2) \\
402(41.8)\end{array}$ \\
\hline $\begin{array}{l}\text { PCT test result } \\
\text { Negative } \\
\text { Positive } \\
\text { Missing }\end{array}$ & $\begin{array}{c}831(86.4) \\
123(12.8) \\
8(0.8)\end{array}$ \\
\hline $\begin{array}{l}\text { WBC classification * } \\
\text { Leukocytopenia } \\
\text { Normal WBCs } \\
\text { Leucocytosis }\end{array}$ & $\begin{array}{c}50(8.2) \\
872(91.4) \\
33(3.4)\end{array}$ \\
\hline $\begin{array}{l}\text { RBCs classification } * * \\
\text { Erythrocytopenia } \\
\text { Normal RBCs Count } \\
\text { Erythrocytosis }\end{array}$ & $\begin{array}{c}170(17.7) \\
751(78.1) \\
41(4.3)\end{array}$ \\
\hline $\begin{array}{l}\text { Hgb classification*** } \\
\text { Anaemia } \\
\text { Normal Haemoglobin } \\
\text { Polycythaemia }\end{array}$ & $\begin{array}{c}265(27.5) \\
693(72.0) \\
4(0.4)\end{array}$ \\
\hline $\begin{array}{l}\text { Platelet classification } * * * \\
\text { Thrombocytopenia } \\
\text { Normal Platelet Count } \\
\text { Thrombocytosis }\end{array}$ & $\begin{array}{c}17(1.8) \\
895(93.0) \\
50(5.2)\end{array}$ \\
\hline 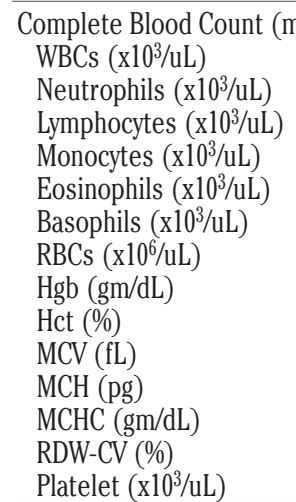 & $\begin{array}{l}\text { D)) } \\
6.81(-2.12) \\
3.82(-1.69) \\
2.28(-0.73) \\
0.46(-0.21) \\
0.19(-0.14) \\
0.05(-0.04) \\
4.79(-0.61) \\
13.22(-1.75) \\
40.01(-4.81) \\
84.03(-7.39) \\
27.77(-2.94) \\
33.01(-1.26) \\
14.21(-2.13) \\
275.97(-71.01)\end{array}$ \\
\hline
\end{tabular}

*WBCs count of 4,000 tol1,000 was considered normal. ** Male RBC normal ranges were 4.7 to 6.1 million cells per microliter (cells/mcL) and for females 4.2 to 5.4 million cells/mcL. ***The normal range for haemoglobin is: For men, 13.5 to 17.5 grams per decilitre. For women, 12.0 to 15.5 grams per decilitre. ${ }^{* * *}$ A normal platelet count ranges from 150,000 to 450,000 platelets per microliter of blood. 
Associations between haematological abnormalities and the likelihood of having a positive COVID-19 PCR test result

Gender was the most influential factor in our sample to increase the odds of having a positive PCR test results; males were more likely to be affected $(\mathrm{P}<0.001$, Chi-square test) (OR 2.56, 95\% CI 1.73-3.77). Categories for haematological abnormalities were not associated with increased risk of having a positive PCT test result; comparing patients with positive and negative PCR test results using chi-square test was not statistically significant (Tables 2 and 3).

Binominal logistic regression analysis was performed to control for gender difference confirmed the statistically nonsignificant difference in the variance between both groups.

\section{Discussion}

In a population attending primary healthcare settings with early presentation of symptoms of COVID-19 infection, the risk of infection among our cohort was not affected by the prior haematological values of those patients.

Gender was the most influential parameter in the risk of infection in our population. Analysis of the results using gender-specific categories for different haematological parameters suggested that patients with abnormal haematological values were not at increased risk of having a positive COVID-19 infection.

Results from the independent t-test analysis for variables suggested that RBCs, haemoglobin, haematocrit counts might play a part, but further analysis confirmed that that is unlikely. RBCs, haemoglobin, and haematocrit counts are all influenced by gender. Male patients have higher counts for all three components compared to females. A plausible explanation for the finding would be that the categorical classification

Table 2. Cross table for the association between gender, WBCs, RBCs and Platelets categories and test result.

\begin{tabular}{|c|c|c|c|c|c|}
\hline & $\mathbf{N}$ & $\begin{array}{l}\text { Negative } \\
(\mathrm{N}=831)\end{array}$ & $\begin{array}{l}\text { Positive } \\
(\mathrm{N}=123)\end{array}$ & Test Statistic & Odds Ratio \\
\hline Gender: Male & 962 & $0.4322 / 831$ & $0.6 \quad 76 / 123$ & $21=23.39, P<0.012$ & $2.56(1.73-3.77)$ \\
\hline $\begin{array}{l}\text { WBC classification* } \\
\text { Leukocytopenia } \\
\text { Normal WBCs } \\
\text { Leucocytosis }\end{array}$ & 962 & $\begin{array}{lr}0.1 & 44 / 831 \\
0.9 & 759 / 831 \\
0.0 & 28 / 831\end{array}$ & $\begin{array}{cc}0.0 & 6 / 123 \\
0.9 & 113 / 123 \\
0.0 & 4 / 123 \\
\end{array}$ & $22=0.04, P=0.982$ & \\
\hline $\begin{array}{l}\text { RBCs Classification** } \\
\text { Erythrocytopenia } \\
\text { Normal RBCs Count } \\
\text { Erythrocytosis }\end{array}$ & 962 & $\begin{array}{lr}0.2 & 148 / 831 \\
0.8 & 649 / 831 \\
0.0 & 34 / 831\end{array}$ & $\begin{array}{cc}0.1 & 18 / 123 \\
0.8 & 98 / 123 \\
0.1 & 7 / 123\end{array}$ & $22=1.29, \mathrm{P}=0.522$ & \\
\hline $\begin{array}{l}\text { Hgb Classification*** } \\
\text { Anaemia } \\
\text { Normal Haemoglobin } \\
\text { Polycythaemia }\end{array}$ & 962 & $\begin{array}{c}0.3227 / 831 \\
0.7600 / 831 \\
0.0 \quad 4 / 831 \\
\end{array}$ & $\begin{array}{cc}0.3 & 34 / 123 \\
0.7 & 89 / 123 \\
0.0 & 0 / 123 \\
\end{array}$ & $22=0.60, P=0.742$ & \\
\hline $\begin{array}{c}\text { Platelet Classification**** } \\
\text { Thrombocytopenia } \\
\text { Normal Platelet Count } \\
\text { Thrombocytosis } \\
\end{array}$ & 962 & $\begin{array}{lr} & \\
0.0 & 14 / 831 \\
0.9 & 775 / 831 \\
0.1 & 42 / 831\end{array}$ & $\begin{array}{cc}0.0 & 2 / 123 \\
0.9 & 113 / 123 \\
0.1 \quad 8 / 123 \\
\end{array}$ & $22=0.45, P=0.802$ & \\
\hline
\end{tabular}

*WBCs count of 4,000 to11,000 was considered normal. **Male RBC normal ranges were 4.7 to 6.1 million cells per microliter (cells/mcL) and for females 4.2 to 5.4 million cells/mcL. ***The normal range for haemoglobin is: For men, 13.5 to 17.5 grams per decilitre. For women, 12.0 to 15.5 grams per decilitre. ${ }^{* * *}$ A normal platelet count ranges from 150,000 to 450,000 platelets per microliter of blood. $\mathrm{N}$ is the number of nonmissing value. 1Kruskal-Wallis. 2Pearson. 3Wilcoxon. Patients with less red blood cell count (RBCs), haemoglobin values (Hgb) and haematocrit value (HCt) were less likely to have a positive PCR test results in our sample of patients attending primary care settings and suspected diagnosis of COVID-19 infection, RBCs $\mathrm{t}(470)=-3.20, \mathrm{p}<.01$, Hgb $\mathrm{t}(470)=-2.77, \mathrm{p}<.01$ and $\mathrm{HCt} \% \mathrm{t}(470)=-3.07, \mathrm{p}<.01$ (Table 3 ).

Table 3. Independent samples T-Test comparison of haematological variance between patients with positive and negative results.

\begin{tabular}{|c|c|c|c|c|c|c|c|c|c|c|}
\hline & Statistic & df & p & $\begin{array}{c}\text { Mean } \\
\text { difference }\end{array}$ & $\begin{array}{c}\text { SE } \\
\text { difference }\end{array}$ & $\begin{array}{c}\text { Lower } 95 \% \\
\text { CI }\end{array}$ & $\begin{array}{c}\text { Upper } 95 \% \\
\text { CI }\end{array}$ & Cohen's d & $\begin{array}{c}\text { Lower } 95 \% \\
\text { CI }\end{array}$ & $\begin{array}{l}\text { Upper } \\
95 \% \text { CI }\end{array}$ \\
\hline WBC $\left(\times 10^{3} / \mathrm{uL}\right)$ & 0.57 & 470 & 0.57 & 0.18 & 0.32 & -0.45 & 0.82 & 0.09 & -0.21 & 0.38 \\
\hline Neutrophils (x103/uL) & 0.96 & 469 & 0.34 & 0.25 & 0.27 & -0.27 & 0.78 & 0.14 & -0.15 & 0.44 \\
\hline Lymphocytes (x103/uL) & -0.37 & 469 & 0.71 & -0.04 & 0.11 & -0.25 & 0.17 & -0.06 & -0.35 & 0.24 \\
\hline Monocytes (x103/uL) & -0.86 & 469 & 0.39 & -0.03 & 0.03 & -0.09 & 0.04 & -0.13 & -0.43 & 0.17 \\
\hline Eosinophils (x103/uL) & -0.65 & 469 & 0.51 & -0.01 & 0.02 & -0.06 & 0.03 & -0.10 & -0.39 & 0.20 \\
\hline Basophils (x103/uL) & -0.17 & 463 & 0.87 & 0.00 & 0.01 & -0.02 & 0.01 & -0.03 & -0.33 & 0.28 \\
\hline $\mathrm{RBCs}\left(\mathrm{x} 10^{6} / \mathrm{uL}\right)$ & -3.20 & 470 & 0.00 & -0.29 & 0.09 & -0.47 & -0.11 & -0.48 & -0.78 & -0.18 \\
\hline $\mathrm{Hgb}(\mathrm{gm} / \mathrm{dL})$ & -2.77 & 470 & 0.01 & -0.70 & 0.25 & -1.19 & -0.20 & -0.42 & -0.72 & -0.12 \\
\hline Hct (\%) & -3.07 & 470 & 0.00 & -2.13 & 0.69 & -3.49 & -0.77 & -0.46 & -0.76 & -0.17 \\
\hline MCV (fL) & 0.27 & 470 & 0.79 & 0.31 & 1.12 & -1.90 & 2.51 & 0.04 & -0.25 & 0.34 \\
\hline MCH (pg) & 0.18 & 470 & 0.86 & 0.08 & 0.45 & -0.80 & 0.96 & 0.03 & -0.27 & 0.32 \\
\hline $\mathrm{MCHC}(\mathrm{gm} / \mathrm{dL})$ & -0.15 & 470 & 0.89 & -0.03 & 0.18 & -0.39 & 0.33 & -0.02 & -0.32 & 0.27 \\
\hline RDW-CV (\%) & -1.36 & 470 & 0.17 & -0.45 & 0.33 & -1.10 & 0.20 & -0.21 & -0.50 & 0.09 \\
\hline Platelet (x103/uL) & 1.73 & 470 & 0.08 & 18.10 & 10.44 & -2.42 & 38.62 & 0.26 & -0.03 & 0.56 \\
\hline
\end{tabular}


reflects the difference through genderspecific values, while continuous variables do not.

Limitations of the study include time to the blood test and the accuracy of PCR test. Patients who had their blood test done before their infection are not representative of the general population and may suffer from other health conditions. To our advantage, most of our sample had normal complete blood count, but results cannot be generalised. Also, the period selected for inclusion may not reflect the actual status of the patient immediately before infection. The long period selected allowed for large enough sample for inclusion. Finally, accuracy of PCR test results is dependent on the technique and operator. Those limitations could form a rationale for further research with shorter time frame to test results e.g. less than 3 months when more extensive pool data is available. Other considerations for future research include a comparison of the haematological changes to those in early COVID-19 cases.

To our knowledge, this is the first study to assess the risk of COVID-19 infection based on haematological laboratory count prior to the infection. Different haematological conditions, including leukocytopenia, leucocytosis, erythrocytopenia, thrombocytopenia, anaemia might not increase the risk of COVID-19 infections. The result may complement our understanding of the condition and does not contradict earlier studies results. Patients with such infections may be at increased risk of severe infection.

\section{References}

1. Centres for Disease Control and Prevention (CDC). Certain Medical Conditions and Risk for Severe COVID19 Illness. Available from: https://www. cdc.gov/coronavirus/2019-ncov/needextra-precautions/people-with-medical-c onditions.html. Accessed: 2020 Aug 3.
2. Almirall J, Serra-Prat M, Bolíbar I, Balasso V. Risk Factors for CommunityAcquired Pneumonia in Adults: A Systematic Review of Observational Studies. Respiration 2017;94:299-311.

3. Almirall J, Bolíbar I, Serra-Prat M, et al. New evidence of risk factors for community-acquired pneumonia: A population-based study. Eur Respir J 2008;31:1274-84.

4. Ramakrishnan M, Moïsi JC, Klugman $\mathrm{KP}$, et al. Increased risk of invasive bacterial infections in African people with sickle-cell disease: A systematic review and meta-analysis. Lancet Infect Dis 2010;10:329-37.

5. Motta I, Migone De Amicis M, Pinto $\mathrm{VM}$, et al. SARS $\square \mathrm{CoV} \square 2$ infection in beta thalassemia: Preliminary data from the Italian experience. Am J Hematol 2020;95:E198-9.

6. Karimi M, Haghpanah S, Azarkeivan A, et al. Prevalence and mortality in $\beta$ thalassaemias due to outbreak of novel coronavirus disease (COVID-19): the nationwide Iranian experience. $\mathrm{Br} \mathrm{J}$ Haematol 2020;190:e137-40.

7. Nur E, Gaartman AE, Tuijn CFJ, et al. Vaso-occlusive crisis and acute chest syndrome in sickle cell disease due to 2019 novel coronavirus disease (COVID-19). Am J Hematol 2020;95: 725-6.

8. Hussain FA, Njoku FU, Saraf SL, et al. COVID-19 infection in patients with sickle cell disease. $\mathrm{Br} \mathrm{J}$ Haematol 2020;189:851-2.

9. Heilbronner C, Berteloot L, Tremolieres $\mathrm{P}$, et al. Patients with sickle cell disease and suspected COVID-19 in a paediatric intensive care unit. $\mathrm{Br} \mathrm{J}$ Haematol 2020;190:e21-4.

10. McCloskey KA, Meenan J, Hall R, Tsitsikas DA. COVID-19 infection and sickle cell disease: a UK centre experience. Br J Haematol 2020;190: e57-8.

11. Härter G, Spinner CD, Roider J, et al. COVID-19 in people living with human immunodeficiency virus: a case series of
33 patients. Infection 2020;14:1.

12. Altuntas Aydin O, Kumbasar Karaosmanoglu H, Kart Yasar K. HIV/SARS-CoV-2 coinfected patients in Istanbul, Turkey. J Med Virol 2020; doi: 10.1002/jmv.25955

13. Gao Y, Chen Y, Liu M, et al. Impacts of immunosuppression and immunodeficiency on COVID-19: A systematic review and meta-analysis. $\mathrm{J}$ Infect 2020;81:e93-5.

14. Lippi G, Plebani M, Henry BM. Thrombocytopenia is associated with severe coronavirus disease 2019 (COVID-19) infections: A metaanalysis. Clin Chim Acta 2020;506: 145-8.

15. Jiang SQ, Huang QF, Xie WM, et al. The association between severe COVID-19 and low platelet count: evidence from 31 observational studies involving 7613 participants. Br J Haematol 2020; 190p:e29-33.

16. Fan BE, Chong VCL, Chan SSW, et al. Hematologic parameters in patients with COVID-19 infection. Am J Hematol 2020;95:E131-4.

17. Terpos E, Ntanasis-Stathopoulos I, Elalamy I, et al. Hematological findings and complications of COVID-19. Am J Hematol 2020;95:834-47.

18. Henry BM, de Oliveira MHS, Benoit S, et al. Hematologic, biochemical and immune biomarker abnormalities associated with severe illness and mortality in coronavirus disease 2019 (COVID-19): a meta-analysis. Clin Chem Lab Med 2020;58:1021-8.

19. Hamed E, Abd Elhamid M, Alemrayat B. Suspected cases of COVID-19: study protocol for reporting characteristics and the outcomes. Fam Med Community Heal 2020;8:400.

20. AlFehaidi AS, Mohamed ZAK, Abd Elhamid M, et al. Why do we need to report on COVID-19 suspected cases presentation in primary care? Int J Community Med Public Heal 2020;7: 2431. 